\title{
O PAPEL DOS ESTUDOS SOBRE MONTEIRO LOBATO NA CONSOLIDAÇÃO DA INTERFACE ESTUDOS DA TRADUÇÃO E LITERATURA INFANTOJUVENIL
}



\author{
Caroline Reis Vieira Santos Rauta, Elisângela Liberatti
}

\begin{abstract}
Resumo: Monteiro Lobato desempenhou importante papel na consolidação da Literatura Infantojuvenil (LIJ) brasileira - tanto como escritor quanto como tradutor desse tipo de literatura. Dentro desse contexto, o objetivo do presente artigo é demonstrar o papel dos estudos sobre Lobato na consolidação da interface Estudos da Tradução (ET) - Literatura Infantojuvenil (LIJ) por meio da realização de um mapeamento da área de pesquisa na intersecção Monteiro Lobato, ET e LIJ. As informações foram retiradas do portal de teses e dissertações da CAPES (http://capesdw.capes.gov.br/capesdw/) e dos acervos digitais das universidades brasileiras que oferecem graduação e pós-graduação stricto sensu em tradução, cobrindo os anos de 1991 a 2014. O mapeamento traz o ano de conclusão da pesquisa, o autor, o título do trabalho, a instituição a que os autores pertencem, a área do conhecimento e um breve resumo da pesquisa. A interpretação dos dados levantados nos permite afirmar que Lobato desempenhou dois importantes papéis para a LIJ brasileira: de maneira direta, foi um dos fundadores da LIJ nacional e, de maneira indireta, foi objeto de estudos que consolidaram as pesquisas acadêmicas realizadas na interface ET e LIJ.
\end{abstract}

Palavras-chave: Monteiro Lobato; Literatura Infantojuvenil; Estudos da Tradução.

\begin{abstract}
Monteiro Lobato had an important role in the consolidation of Brazilian Children's Literature - both as a writer and translator of this kind of texts. In that context, the purpose of this paper is to demonstrate the role of the studies on Lobato in the consolidation of the interface Translation Studies (TS) - Children's Literature (CL) through a mapping of the research area in the intersection Monteiro Lobato, ET, CL. The information presented here were taken from CAPES' MA dissertations and $\mathrm{PhD}$ thesis portal and from the digital collection of Brazilian universities that offer undergraduate and stricto sensu graduate programs in Translation, covering the years from 1991 to 2014. The mapping brings the year of conclusion of each research, the author, the title, the institution to which the authors are affiliated to, the area of knowledge and a brief abstract of the research. Based on the data found, it is possible to state that Lobato has played two important roles in the development of Brazilian CL: directly, he was one of the founders of the national CL; indirectly, he was object of some studies that consolidated academic research in the interface TS - CL.
\end{abstract}

Keywords: Monteiro Lobato; Children's Literature; Translation Studies. 
$\mathrm{J}$ osé Bento Monteiro Lobato envolveu-se ao longo de sua vida em diversas atividades profissionais: foi pintor, panfletário, escritor, editor, revisor, tradutor, crítico literário e artístico, jornalista, fazendeiro, diplomata, promotor e empresário (FRANCA, 2009). Seu legado cultural é substancioso e pode-se considerar o autor como um dos precursores da Literatura Infantojuvenil (LIJ) nacional em uma época em que as obras lidas pelos jovens leitores brasileiros eram ainda aquelas traduzidas para o português europeu (LAJOLO; ZILBERMAN, 1999). As obras de LIJ escritas por Lobato continham suas próprias visões políticas, e as obras adaptadas por ele continham visões políticas afins às suas próprias, as quais não iam ao encontro das políticas protecionistas e nacionalistas do governo Getúlio Vargas (1930 - 1945) (MILTON, 2003).

Tendo em vista o grande número e a importância da produção literária para crianças e jovens de Lobato, não é de causar grande espanto que algumas das primeiras teses e dissertações cadastradas no portal de teses e dissertações da Comissão de Aperfeiçoamento de Pessoal de Nível Superior (CAPES) cobrindo a interface LIJ e Estudos da Tradução (ET) investigaram a produção Lobatiana para leitores não adultos.

Dentro desse contexto, o principal objetivo deste artigo é demonstrar o papel dos estudos sobre Monteiro Lobato na consolidação da interface LIJ - ET, oferecendo um mapeamento da intersecção Monteiro Lobato, LIJ e ET. Dessa forma, serão apresentados todos os trabalhos encontrados que investigaram as obras infantojuvenis traduzidas por Lobato e as obras infantojuvenis lobatianas traduzidas para outras línguas. Antes de apresentar as pesquisas mapeadas, todavia, contextualizar-se-á o papel de Lobato como tradutor e autor traduzido de Literatura Infantojuvenil.

\section{Monteiro Lobato Escritor e Tradutor de Literatura Infantojuvenil}

O projeto de Lobato de criar uma literatura nacional surgiu com seu primeiro livro dedicado ao público infantojuvenil, “A Menina do Nariz Arrebitado”, publicado em 1921. Em seguida foram lançados mais 23 livros na coleção "O Sítio do Pica Pau Amarelo" e cerca de 16 outros títulos também dedicados ao público infantojuvenil (VIEIRA, 2001). O intuito do autor era escrever obras que pudessem ser lidas para crianças e por crianças brasileiras, abandonando as edições escritas em português europeu que "não tinham, com os pequenos leitores brasileiros, sequer a cumplicidade do idioma" (LAJOLO, ZILBERMAN, 1999, p. 30).

Antes da iniciativa de Lobato, o português europeu e o francês eram as línguas dominantes nas obras importadas para o Brasil, como explica John Milton: “Antes de Lobato, a maioria das publicações estava nas mãos de empresas pertencentes a Portugal ou à França, e o mercado-alvo era primordialmente a elite francófila de classe média”"1(MILTON, 2003, p. 212, tradução nossa).

Além das adaptações linguísticas, Lobato incorporou a sua obra a realidade dos leitores brasileiros, tanto como escritor quanto como tradutor. Na condição de tradutor, Lobato via a necessidade de trazer ao jovem leitor obras escritas originalmente em outras línguas que não o francês, como o inglês, o alemão e o russo. Para além disso, a ideia de Lobato era também a de adaptar as obras traduzidas, “[...] usando linguagem simples e

\footnotetext{
1 "Until Lobato, most publishing was in the hands of Portuguese or French-owned companies, and the target market was very much that of the Francophile middle-class elite".
} 
mais coloquial, que deveria imediatamente ser entendida pelas crianças, o público-alvo de Lobato"2 (MILTON, 2003, p. 215, tradução nossa). Segundo ele, a LIJ teria de estar "livre” de tudo que pudesse minar a imaginação da criança e seu entretenimento - com isso, Lobato reunia esforços para que a linguagem de suas obras fosse simples, leve e fluente (MILTON, 2003). Essa adaptação da realidade não se limitou apenas à adaptação linguística. Em alguns casos do "Sítio do Pica-Pau Amarelo", por exemplo, Lobato adapta a trama através da voz de Dona Benta, que reconta histórias estrangeiras incorporando explicações ou fazendo adaptações ao contexto brasileiro. Além disso, ele se apropria de personagens estrangeiros (VIEIRA, 2001) e os insere nas aventuras do livro.

Lobato também teve suas obras traduzidas para diversos idiomas-: inglês, espanhol, francês, russo, alemão, japonês, entre outros (FRANCA, 2009). Algumas de suas obras infantojuvenis traduzidas foram: "D. Quixote das crianças”, de 1938,; "Emília no país da Gramática”, de 1943; e "Reinações de Narizinho”, de 1944, todas traduzidas para o espanhol; "O engraçado arrependido", de 1947, para o inglês; "O saci”, de 1979, para o japonês; entre outras (AZEVEDO; CAMARGOS; SACCHETA, 1997; CAVALEIRO, 1955).

Como se pode perceber a partir do acima exposto, Monteiro Lobato contribui para a produção de LIJ não somente como escritor, mas também como tradutor, além de ter suas obras infantojuvenis exportadas para vários cantos do mundo. Dessa forma, serão apresentados adiante os dados referentes à produção de pesquisas acadêmicas realizadas na interface Monteiro Lobato, ET e LIJ, levantados a partir do portal de teses e dissertações da CAPES e dos acervos digitais das universidades brasileiras que oferecem graduação e pósgraduação stricto sensu em tradução ${ }^{34}$, a fim de quantificar o que vem sendo pesquisado sobre o assunto..

\section{Método do levantamento}

A CAPES disponibiliza um portal de teses e dissertações em que os programas de pós-graduação strictu sensu do país cadastram os resumos e outras informações paratextuais (como agência financiadora, área do conhecimento, autor, biblioteca, data da defesa, instituição de ensino, linha de pesquisa, nível, orientador, palavras-chave, programa e título) dos trabalhos defendidos. O portal tem registros de trabalhos concluídos a partir de 1987. Esse portal foi utilizado como principal fonte de coleta de dados e, sempre que necessário, consultaram-se também as bibliotecas online das universidades e programas de pós-graduação, e a página do "Domínio Público"5, em que se encontram alguns dos trabalhos na íntegra.

Para fazer a busca no portal da CAPES foram utilizados os seguintes termos de busca: "Lobato", “Monteiro Lobato”, "Estudos da Tradução”, “tradução de literatura infanto-juvenil”, "tradução de literatura infantojuvenil”, "literatura infanto-juvenil”, "literatura infantojuvenil”, "Lobato tradutor", "Monteiro Lobato tradutor”, "Lobato

\footnotetext{
2 “[...] using a more simplified and colloquial language, which could immediately be understood by children, Lobato’s target audience”.

${ }^{3}$ Até o momento de confecção deste artigo (2015), no Brasil temos 27 cursos de graduação em Tradução e 4 cursos de pós-graduação stricto sensu.

${ }^{4}$ A consulta ao acervo digital de uma das universidades levantadas (Universidade Federal do Ceará) funciona apenas como intranet, permitindo acesso apenas a usuários cadastrados com senha, e, por isso, não foi possível realizar a consulta ao acervo digital dessa universidade.

${ }^{5}$ Disponível em: www.dominiopublico.gov.br
} 
traduzido" e "Monteiro Lobato traduzido". Depois, foram levantados os trabalhos que cobrem a área de intersecção de nosso interesse: ET, Lobato e LIJ.

Os resumos que emergiram dessa busca são apresentados na seção 3 a seguir, junto das informações acerca do desenvolvimento das pesquisas, como os nomes dos autores, as naturezas de seus trabalhos, os anos de conclusão, e as instituições de ensino superior e as área do conhecimento a qual a tese ou dissertação se filiou. Esses dados foram sistematizados em uma tabela para facilitar sua visualização e interpretação.

Foi a partir de tal levantamento que se notou que no âmbito nacional houve um aumento gradativo nos últimos 30 anos do interesse na área de pesquisa que abrange a intersecção entre Estudos da Tradução e LIJ, o que é possível de ser observado através do número crescente de teses e dissertações defendidas na área e cadastradas no portal de teses e dissertações da CAPES ${ }^{6}$. Dentre essas pesquisas, há aquelas que investigam especificamente as traduções feitas por Lobato ou as traduções de suas obras, cobrindo, assim, a área de intersecção ET e Monteiro Lobato. Como este artigo tem como objetivo principal mapear as pesquisas realizadas sobre Lobato no campo disciplinar dos ET na área de LIJ (interface ET, Lobato e LIJ), as pesquisas que tiveram como temática a intersecção entre os ET e a obra de literatura adulta de Lobato não foram incluídas no mapeamento apresentado.

\section{Resultados}

Conforme pesquisa realizada no portal de teses e dissertações da Capes e nos acervos digitais de universidades brasileiras ${ }^{7}$ que oferecem cursos de graduação e pósgraduação stricto sensu em tradução, existem, até 2014, 21 pesquisas na intersecção ET, Monteiro Lobato e LIJ, sendo que 16 trabalhos são dissertações de mestrado e cinco são teses de doutorado. Durante a década de 1990 foram realizados os dois primeiros trabalhos: a tese de Vargas (1991) e a dissertação de Trusen (1995). A partir dos anos 2000 é que passam a ganhar fôlego não só as pesquisas desenvolvidas na interface ET-LIJ em geral, mas também trabalhos sobre a atuação de Lobato como tradutor e como autor traduzido: nesse período foram defendidas 14 dissertações de mestrado (ALENCAR, 2005; BÖHN, 2001; CORDEIRO, 2005; COSTA, 2008; CRUZ, 2011; FRANCA, 2007; GARCIA, 2010; MAXIMO, 2004; MENDES, 2005; POZZATI, 2014; SILVA, 2008; VOLKER, 2005; WHITE, 2011; ZORZATO, 2007) e cinco teses de doutorado (OLIVEIRA, 2007; PALLOTTA, 2001; ROCHA, 2002; RODRIGUES, 2006; VIEIRA, 2004).

O número de teses e dissertações desenvolvidas manteve-se constante durante os anos 2000, não havendo concentração de pesquisas de certa natureza (dissertação e mestrado) em um determinado período (consulte o gráfico dois para melhor visualização). Ademais, não houve um ano em particular que chamasse atenção pelo número de trabalhos concluídos. Há dois motivos que podem ser levantados para justificar a maior produtividade a partir dos anos 2000 em relação à década anterior: o primeiro deles diz respeito ao acesso cada vez maior da população ao ensino superior ao longo dos anos,

\footnotetext{
${ }^{6}$ Disponível através da página http://capesdw.capes.gov.br/capesdw/.

${ }^{7}$ As universidades pesquisadas que apresentam acervo digital foram a UNASP, UNIBERO, FIBRA, FMU, PUC-RJ, UFRGS, UFMG, UFPR, UFRJ, UFSC, UFU, Unesp, UNILAGO, UNIMEP, UNIP, UNIDERP, Unisantos, Unifran, USC, UECE, UFPB, UFJF, UFOP, UFPEL, UNINOVE e Universidade São Judas Tadeu. Essas universidades em particular foram consultadas devido a terem curso de graduação em tradução, segundo o levantamento feito por Liberatti (no prelo).
} 
principalmente no que diz respeito à pós-graduação (BALBACHEVSKY, 2005); o segundo motivo pode ser atribuído à dificuldade de registro das teses e dissertações anteriores a esse ano no portal eletrônico da CAPES, uma vez que, na década de 1990, principalmente no início, o computador pessoal não era tão acessível, o que pode ter dificultado o registro retroativo desde 1987 por parte dos programas de pós-graduação, responsáveis por inserir os trabalhos defendidos no referido portal de teses e dissertações.

Segundo Grbic (2007), as teses exigem maior foco no objeto de estudo e anos de trabalho intenso. Em virtude dessa exigência de maior dedicação por parte do pesquisador, da disponibilidade dos orientadores e do tempo de conclusão da pesquisa de doutorado (o dobro de tempo se comparado ao mestrado, normalmente), é razoável supor que o número de pesquisas de doutorado seja naturalmente menor do que o de mestrado. Todavia, um número expressivo de teses também pode indicar certo amadurecimento da área. Os dados encontrados neste mapeamento revelam que o número de dissertações é mais de três vezes maior em relação às teses. Apesar disso, o número de trabalhos que observam a produção de Lobato tradutor e traduzido é representativo, em que $23,8 \%$ do total de pesquisas são teses.

Os trabalhos envolvendo as traduções feitas por Lobato e as traduções de suas obras foram desenvolvidos junto a programas de Pós-graduação de diferentes áreas do conhecimento: Letras; Linguística e Letras; Linguística Aplicada; Estudos Linguísticos; Literatura (Teoria, Crítica e História); e Educação. Isso é uma amostra de que a intersecção dos ET com a LIJ pode ser explorada de maneira bastante diversificada e interdisciplinar, sendo uma área de pesquisa muito produtiva. Esses programas de Pós-Graduação estão filiados a 12 Instituições de Ensino Superior (IES) diferentes, com destaque para a Universidade Estadual de Campinas (Unicamp) - com quatro trabalhos - e para a Universidade Federal do Rio de Janeiro (UFRJ), a Universidade de São Paulo (USP), a Universidade Estadual Paulista Júlio De Mesquita Filho em Assis (Unesp - Assis) e a Universidade Federal do Ceará (UFC) - com dois trabalhos cada. As demais instituições, com um trabalho cada, serão apresentadas mais adiante nesta subseção, junto com os resumos das pesquisas. Não se observou nenhum padrão que justificasse por que essas IES tiveram maior representatividade em relação às outras e nenhum dos orientadores dos trabalhos encontrados orientou mais de uma das pesquisas citadas no artigo.

Outro dado que nos chamou a atenção diz respeito à autoria dos trabalhos, não só envolvendo a obra de Lobato tradutor e traduzido, mas também pesquisas envolvendo a tradução de LIJ de forma geral: a maioria das pesquisas foi realizada por mulheres (são seis autores e quarenta e uma autoras). Essa característica pode estar relacionada ao status inferior que vinha sendo atribuído à LIJ (SHAVIT, 2003), sendo uma literatura, então, escrita, traduzida e pesquisada por uma minoria (no caso, principalmente, as mulheres) e para outra minoria (as crianças); e pelo fato de as mulheres estarem mais ligadas à educação das crianças e jovens do que os homens (AMORIM, 2011). Não é nosso intuito, no entanto, fazer uma discussão abrangente sobre gênero neste momento, mas o fato chamou bastante nossa atenção e merece investigações futuras.

Abaixo, trazemos maiores detalhes sobre cada uma das pesquisas encontradas: os nomes dos autores, os respectivos anos de conclusão de cada trabalho, a instituição a que os autores pertencem, a área do conhecimento do Programa de Pós-Graduação junto ao qual os trabalhos foram desenvolvidos e um breve resumo de cada um deles. Como em muitos casos tivemos acesso somente às informações disponíveis no portal da CAPES e nos acervos digitais das universidades, e essas informações nem sempre estavam 
completas, os breves resumos das pesquisas aqui apresentados nem sempre trazem detalhes sobre metodologia, resultados e conclusões.

1. Maria Valiria A. Melo Vargas (1991, Doutorado, USP, Linguística) "Do Pancatantra a La Fontaine: Tradução e Permanência da Fábula": o objeto de estudo da tese de Vargas são quatro fábulas de Lobato, a versão portuguesa de Hitopadeca, de S.R. Delgado, e fábulas de La Fontaine. O objetivo central da tese é argumentar que as marcas de oralidade, intencionalidade e intertextualidade presentes nas fábulas indianas de Pancatantra e nos textos de La Fontaine são os principais contribuintes para a confirmação e permanência da fábula como gênero literário.

2. Sylvia Maria Trusen (1995, Mestrado, UFC, Letras) “Os Grimm No Sitio Do Pica-pau Amarelo: Tradução e Recepção dos Contos de Grimm em Monteiro Lobato”: Trusen investiga a postura de vanguarda de Lobato em relação à tradução de obras de ficção europeias, mais precisamente os contos-de-fada, para o público infantojuvenil brasileiro. A autora estuda a proposta do autor de viabilizar a circulação das obras literárias infantojuvenis consideradas clássicas através da atualização da linguagem de acordo com as necessidades do polo receptor. ${ }^{8}$

3. Gabriela Cassilda Hardtke Böhn. (2001, Mestrado, PUC-RS ${ }^{9}$, Linguística e Letras) "Peter Pan para crianças brasileiras: a adaptação de Monteiro Lobato para a obra de James Joice": Böhn pesquisa a tradução de "Peter Pan e Wendy" (BARRIE, 1911), feita por Monteiro Lobato (1930), observando o abrasileiramento da obra inglesa através da adaptação feita por Dona Benta, personagem que narra a história, o que tornou o texto mais acessível a crianças e jovens brasileiros.

4. Miriam Giberti Páttaro Pallotta (2001, Doutorado, Unesp-SJRP, Letras) "Uma História Meio ao Contrário: um Estudo sobre 'História do Mundo para as Crianças' De Monteiro Lobato": neste estudo foram analisadas as obras "História do Mundo para as Crianças", de Monteiro Lobato, o original A Child's History of the World e "Pequena História do Mundo para Crianças”, de Godofredo Rangel. O estudo mostra que a obra lobatiana apresenta uma configuração diferenciada em relação às outras obras através de um redimensionamento da obra original. As personagens da tradução de Lobato interferem na narrativa com novos pontos de vista sobre os assuntos abordados. A autora também aborda a polêmica gerada em torno da obra.

5. Pedro Albeirice da Rocha (2002, Doutorado, Unesp-SJRP, Letras) "Monteiro Lobato reescritor de Kipling”: A tese estuda as traduções feitas por Monteiro Lobato de The Jungle Book (1894), The Second Jungle Book (1895) e Kim (1901), de Rudyard Kipling, sob o olhar dos Estudos Descritivos da Tradução levando em conta o papel do contexto cultural nas reescrituras. Na última parte o autor faz uma comparação entre textos fonte e alvo com o objetivo de verificar os procedimentos de tradução recorrentes e tentar formular hipóteses explicativas para a escolha de tais procedimentos.

6. Adriana Silene Vieira. (2004, Mestrado, Unicamp, Teoria e História Literária) "Viagens de Gulliver ao Brasil (Estudo das Adaptações de Gulliver's Travels por Carlos Jansen e por Monteiro Lobato": Vieira fez uma comparação entre Gulliver's Travels (1726) e as primeiras adaptações brasileiras feitas por Carlos Jansen (1888) e Monteiro Lobato (1937), respectivamente para estudantes do Colégio D. Pedro II e crianças

\footnotetext{
${ }^{8} \mathrm{O}$ resumo cadastrado no portal de teses e dissertações da CAPES está incompleto e fornece informações limitadas, não trazendo mais detalhes sobre metodologia, resultados e conclusões.

${ }^{9}$ Pontifícia Universidade Católica do Rio Grande do Sul.
} 
brasileiras em geral, discutindo problemas de adaptação, tradução e recepção e as relações entre o texto, o intermediário (tradutor, adaptador) e o público a quem o texto se destina.

7. Gustavo Maximo (2004, Mestrado Unicamp, Linguística Aplicada) "Duas personagens em uma Emília nas traduções de Monteiro Lobato": essa dissertação investiga a contiguidade das personagens principais Alice e Pollyana com a boneca Emília nas traduções Alice's Adventures in Wonderland, de Lewis Carroll, e "Pollyana”, de Eleanor H. Porter. Segundo o autor, essa contiguidade descaracteriza a Alice britânica e a Pollyana norte-americana. Para realizar sua análise, Maximo compara as traduções de Lobato com as de Ana Maria Machado, no caso de “Alice no País das Maravilhas”, e de Paulo Silveira, no caso de "Pollyana". O resultado encontrado é que as traduções lobatianas trazem uma mistura de Emília com as protagonistas das obras traduzidas.

8. Socorro Edite Oliveira Acioli de Alencar (2004, Mestrado, UFC, Letras) "De Emília a Dona Quixotinha, uma aula de leitura com Monteiro Lobato": a dissertação de Alencar observa o projeto lobatiano de formação de leitores-agentes, cujo principal agente é a personagem Emília. Mais especificamente, o trabalho investigou a atuação de Emília na tradução "Dom Quixote das Crianças” feita por Lobato, em que a personagem passou a se autodenominar Dona Quixotinha, influenciada pelas ideias do personagem principal. A autora analisa como Monteiro Lobato ensinou a ler nos seus livros infantis, como tratou o posicionamento do leitor-agente em relação aos textos e analisou as práticas de leitura-ação da boneca Emília.

9. Mariana Sbaraini Cordeiro (2005, Mestrado, UEL ${ }^{10}$, Letras) "Mark Twain na vitrine de Lobato": Cordeiro investiga a tradução de Huckleberry Finn feita por Lobato usando a teoria da invisibilidade de Venuti. São analisadas a oralidade do dialeto do negro do Missouri na fala do personagem Jim e as inserções feitas por Lobato de expressões coloquiais inexistentes no texto de partida. A conclusão da autora é que Lobato domesticou sua tradução através da inserção de vocábulos e expressões coloquiais.

10. Taciana Bylaardt Volker (2005, Mestrado, UFMG, Estudos Linguísticos) “A Tradução das expressões idiomáticas por Monteiro Lobato em "The Adventures of Huckleberry Finn": uma análise à luz da teoria da relevância”: essa pesquisa investiga a tradução por Monteiro Lobato das expressões idiomáticas presentes no livro The Adventures of Huckleberry Finn, de Mark Twain. A autora usa como arcabouço teórico a teoria da relevância de Sperber \& Wilson (1986/1995), a aplicação dessa teoria para os ET, feita por Ernst-August Gutt (2000), e, para a interpretação de expressões idiomáticas, a teoria desenvolvida por Vega-Moreno (2001/2004). Os resultados obtidos são que Lobato adapta o texto de partida ao ambiente cognitivo do público-alvo, o que levou a omissões e paráfrases como estratégias que transformam implicaturas da expressão idiomática original em explicaturas na tradução. Conclui-se que as estratégias usadas por Lobato são congruentes com seus objetivos.

11. Denise Rezende Mendes (2005, Mestrado, CES/JF"11, Letras) "Monteiro Lobato, as múltiplas faces do idealista: editor, tradutor e autor de obras infanto-juvenis”: o objetivo desta pesquisa é apresentar uma comparação entre as obras literárias "O escândalo do petróleo e ferro" e "O poço do Visconde", com o intuito de demonstrar a maneira pela qual Lobato tentou passar para as crianças sua ideologia nacionalista.

\footnotetext{
${ }^{10}$ Universidade Estadual de Londrina

${ }^{11}$ Centro de Ensino Superior de Juiz de Fora
} 
12. Elizamari Martins Rodrigues (2006, Doutorado UFRGS ${ }^{12}$, Letras) "Forças motrizes de uma contística pré-modernista: o papel da tradução na obra ficcional de Monteiro Lobato": o objetivo deste trabalho é analisar três forças motrizes que influenciaram as escrituras de Lobato: o conto, a tradução e a ideologia humanista. A autora analisa a contribuição de Lobato ao polissistema literário brasileiro, sua literatura e sua ideologia. Aborda o fato de Lobato, tendo traduzido mais de 100 livros, ter contribuído tanto para a circulação quanto para a edição de obras traduzidas, enriquecendo, com isso, o polissistema literário e promovendo mudança no status da tradução.

13. Lucila Bassan Zorzato. (2007, Mestrado, Unicamp, Teoria e História Literária) "A Cultura Alemã na Obra Infantil Aventuras de Hans Staden, de Monteiro Lobato": Zorzato investiga a relação de Monteiro Lobato com a cultura alemã através das obras "Meu cativeiro entre os selvagens do Brasil" (1925) e "Aventuras de Hans Staden" (1927). A pesquisa investiga, através da análise de documentos e da correspondência lobatiana, a representação da cultura alemã para Lobato, as propostas de versão de sua obra para o alemão, sua recepção entre leitores de língua alemã e a relação do autor com a própria língua.

14. Vanessa Gomes Franca (2007, Mestrado, UFG ${ }^{13}$, Letras e Linguística). "A Literatura Infantil/Juvenil brasileira na França: où est Lobatô?”: Franca investiga as obras infantojuvenis brasileiras presentes na França, sejam elas traduzidas para o francês ou editadas diretamente em francês. A autora fez um estudo de elementos paratextuais e textuais por meio de cotejo de fragmentos de algumas dessas obras e suas traduções. São abordados aspectos interlinguais e intersemióticos. O esquema proposto por José Lambert e Hendrik Van Gorp para a descrição de traduções serviu-lhe de apoio.

15. Maria Lilia Simões de Oliveira (2007, Doutorado, UFRJ, Letras) "Nas dobras da memória: a linguagem dos clássicos e suas adaptações”: A linguagem das adaptações de clássicos universais para leitores iniciantes é estudada nesta tese. O objeto de estudo da pesquisa é a obra Dom Quixote de La Mancha, de Miguel de Cervantes. A tese faz uma comparação entre a versão integral da obra e as paráfrases de Monteiro Lobato e de Ferreira Gullar, observando a capacidade de o autor / adaptador trabalhar esteticamente o texto adaptado, elaborando-o com linguagem mais acessível, mas mantendo a marca do original.

16. Cynthia Beatrice Costa (2008, Mestrado, PUC-SP, Literatura e Crítica Literária) "Versões de Alice no País das Maravilhas: da tradução à adaptação de Carroll no Brasil": Costa, em sua pesquisa, discute a qualidade literária da tradução para o português da obra “Alice no País das Maravilhas”, de Lewis Carroll. A discussão envolve o confronto tradução versus adaptação do texto fonte, analisando-se as obras traduzidas por quatro autores e tradutores brasileiros: Monteiro Lobato, Sebastião Uchoa Leite, Ana Maria Machado e Ruy Castro.

17. Adriana Paula Dos Santos Silva (2008, Mestrado, UEM ${ }^{14}$, Letras) “Amoras Sem Espinhos: A Recepção de Fábulas (1922), de Monteiro Lobato, por Crianças do Ensino Fundamental”: o objeto de estudo desta pesquisa são 22 fábulas retiradas do livro "Monteiro Lobato". Seu objetivo é analisar a recepção de textos literários por crianças do primeiro ciclo do ensino fundamental. Parte do trabalho aborda os recursos de adaptação e

\footnotetext{
${ }^{12}$ Universidade Federal do Rio Grande do Sul.

${ }^{13}$ Universidade Federal de Goiás.

${ }^{14}$ Universidade Estadual de Maringá.
} 
tradução literárias e da paródia como instrumentos utilizados na reescrita lobatiana, verificando a influência de tais recursos na constituição do texto narrativo.

18. André Aparecido Garcia (2010, Mestrado, Unicamp, Educação) “Orlando Furioso de Lobato: uma obra inconclusa”: os objetivos da pesquisa de Garcia são: realizar um levantamento da criação e difusão pela Europa de Orlando Furioso de Ariosto; refletir sobre os aspectos tipográficos de Orlando Furioso vertido para o português por Xavier da Cunha em 1895 e analisar as estratégias textuais de edição utilizadas por Lobato na adaptação de Orlando Furioso, traduzido por Xavier da Cunha, para o leitor infantil.

19. Shirley da Cruz (2011, Mestrado, UFRJ, Interdisciplinar Linguística Aplicada) "Um passeio pelas diversas traduções de Alice no País das Maravilhas de Lewis Carroll no português do Brasil”: o objetivo dessa pesquisa é apresentar uma análise descritiva de várias edições da tradução para o português brasileiro de "Alice no País das Maravilhas" realizadas por Lobato. As principais conclusões obtidas demonstram que Lobato utilizou alguns métodos para a tradução da obra, tais como: expandir e omitir partes do texto fonte. Concluiu-se também que as reedições das traduções de Lobato passaram por alterações ao longo dos anos sem quaisquer menções por parte das editoras.

20. Vera Lucia White (2011, Mestrado USP, Estudos Linguísticos e Literários em Inglês) "A influência do filme de Walt Disney nas traduções e adaptações brasileiras de Peter Pan entre 1953 e 2011”: White, em sua pesquisa, analisa edições impressas de Peter Pan publicadas no Brasil (em português brasileiro) de 1930 até 2011. O que a autora propõe é a existência de uma norma ao se traduzir Peter Pan durante os anos estudados: a de se utilizar a versão em desenho animado longa-metragem de Walt Disney como parâmetro, principalmente no que concerne à purificação do texto e ilustrações. Na pesquisa, algumas obras recebem maior destaque em função de sua importância referencial e histórica; entre elas, a adaptação de Monteiro Lobato.

21. Silvia Pozzati (2014, Mestrado USP, Língua, Literatura e Cultura Italianas) “A chave do tamanho: proposta de edição da obra de Monteiro Lobato na Itália”: A pesquisa de Pozzati traz as obras infantojuvenis Narizinho e A Chave do Tamanho como parte importante da produção de um dos mais ricos e interessantes autores brasileiros do século XX, Monteiro Lobato. A pesquisa evidencia o valor seminal desses trabalhos e seus aspectos mais significativos, tanto na tradução de Narizinho para o italiano quanto no texto original de A Chave do Tamanho, ainda sem tradução para a língua italiana. As questões sobre a linguagem e sobre a estrutura das obras infantis de Lobato são discutidas nessas suas duas obras. A autora analisa termos presentes nas obras que considera desafios de tradução, sendo A Chave do Tamanho o centro de análise da dissertação.

O quadro a seguir sintetiza os dados dos trabalhos que investigam o papel de Lobato como tradutor de LIJ e como autor de obras infantojuvenis posteriormente traduzidas. Os gráficos ilustram o breve panorama dos trabalhos encontrados:

\begin{tabular}{|c|c|c|c|c|}
\hline Autor & $\begin{array}{l}\text { Natureza } \\
\text { do trabalho }\end{array}$ & $\begin{array}{c}\text { Ano de } \\
\text { conclusão }\end{array}$ & Instituição & $\begin{array}{c}\text { Área do } \\
\text { conhecimento }\end{array}$ \\
\hline $\begin{array}{l}\text { 1. Maria Valiria } \\
\text { A. Melo Vargas }\end{array}$ & Dissertação & 1991 & $\begin{array}{c}\text { Universidade de São } \\
\text { Paulo }\end{array}$ & Linguística \\
\hline $\begin{array}{ll}\text { 2. Sylvia } & \text { Maria } \\
\text { Trusen } & \\
\end{array}$ & Dissertação & 1995 & $\begin{array}{c}\text { Universidade Federal } \\
\text { do Ceará }\end{array}$ & Letras \\
\hline $\begin{array}{l}\text { 3. Gabriela } \\
\text { Cassilda Hardtke } \\
\text { Böhn }\end{array}$ & Dissertação & 2001 & $\begin{array}{c}\text { Pontifícia Universidade } \\
\text { Católica do Rio Grande } \\
\text { do Sul }\end{array}$ & $\begin{array}{l}\text { Linguística e } \\
\text { Letras }\end{array}$ \\
\hline
\end{tabular}




\begin{tabular}{|c|c|c|c|c|}
\hline Autor & $\begin{array}{c}\text { Natureza } \\
\text { do trabalho }\end{array}$ & $\begin{array}{c}\text { Ano de } \\
\text { conclusão }\end{array}$ & Instituição & $\begin{array}{c}\text { Área do } \\
\text { conhecimento }\end{array}$ \\
\hline $\begin{array}{l}\text { 4. Miriam Giberti } \\
\text { Páttaro Pallotta }\end{array}$ & Tese & 2001 & $\begin{array}{l}\text { Universidade Estadual } \\
\text { Paulista “Júlio de } \\
\text { Mesquita Filho”- } \\
\text { campus São José do Rio } \\
\text { Preto }\end{array}$ & Letras \\
\hline $\begin{array}{l}\text { 5. Pedro Albeirice } \\
\text { Da Rocha }\end{array}$ & Tese & 2002 & $\begin{array}{l}\text { Universidade Estadual } \\
\text { Paulista “Júlio de } \\
\text { Mesquita Filho" - } \\
\text { campus São José do Rio } \\
\text { Preto }\end{array}$ & Letras \\
\hline $\begin{array}{l}\text { 6. Adriana Silene } \\
\text { Vieira }\end{array}$ & Tese & 2004 & Unicamp & $\begin{array}{l}\text { Teoria e } \\
\text { História } \\
\text { Literária } \\
\end{array}$ \\
\hline $\begin{array}{l}\text { 7. Gustavo } \\
\text { Maximo }\end{array}$ & Dissertação & 2004 & Unicamp & $\begin{array}{l}\text { Linguística } \\
\text { Aplicada }\end{array}$ \\
\hline $\begin{array}{l}\text { 8. Socorro Edite } \\
\text { Oliveira Acioli de } \\
\text { Alencar }\end{array}$ & Dissertação & 2004 & $\begin{array}{l}\text { Universidade Federal } \\
\text { do Ceará }\end{array}$ & Letras \\
\hline $\begin{array}{l}\text { 9. Mariana } \\
\text { Sbaraini Cordeiro }\end{array}$ & Dissertação & 2005 & $\begin{array}{l}\text { Universidade Estadual } \\
\text { de Londrina }\end{array}$ & Letras \\
\hline $\begin{array}{l}\text { 10. Taciana } \\
\text { Bylaardt Volker }\end{array}$ & Dissertação & 2005 & $\begin{array}{l}\text { Universidade Federal } \\
\text { de Minas Gerais }\end{array}$ & $\begin{array}{c}\text { Estudos } \\
\text { Linguísticos }\end{array}$ \\
\hline $\begin{array}{l}\text { 11. Denise Rezende } \\
\text { Mendes }\end{array}$ & Dissertação & 2005 & $\begin{array}{l}\text { Centro de Ensino } \\
\text { Superior de Juiz de } \\
\text { Fora } \\
\end{array}$ & Letras \\
\hline $\begin{array}{l}\text { 12. Elizamari } \\
\text { Martins Rodrigues }\end{array}$ & Tese & 2006 & $\begin{array}{l}\text { Universidade Federal } \\
\text { do Rio Grande do Sul }\end{array}$ & Letras \\
\hline $\begin{array}{l}\text { 13. Lucila Bassan } \\
\text { Zorzato }\end{array}$ & Dissertação & 2007 & Unicamp & $\begin{array}{l}\text { Teoria e } \\
\text { História } \\
\text { Literária }\end{array}$ \\
\hline $\begin{array}{l}\text { 14. Vanessa Gomes } \\
\text { Franca }\end{array}$ & Dissertação & 2007 & $\begin{array}{c}\text { Universidade Federal } \\
\text { de Goiás }\end{array}$ & $\begin{array}{c}\text { Letras e } \\
\text { Linguística } \\
\end{array}$ \\
\hline $\begin{array}{l}\text { 15. Maria Lilia } \\
\text { Simões de Oliveira }\end{array}$ & Tese & 2007 & $\begin{array}{l}\text { Universidade Federal } \\
\text { do Rio de Janeiro }\end{array}$ & Letras \\
\hline $\begin{array}{l}\text { 16. Cynthia } \\
\text { Beatrice Costa }\end{array}$ & Dissertação & 2008 & $\begin{array}{l}\text { Pontifícia Universidade } \\
\text { Católica de São Paulo }\end{array}$ & $\begin{array}{l}\text { Literatura e } \\
\text { Crítica } \\
\text { Literária }\end{array}$ \\
\hline $\begin{array}{l}\text { 17. Adriana Paula } \\
\text { dos Santos Silva }\end{array}$ & Dissertação & 2008 & $\begin{array}{c}\text { Universidade Estadual } \\
\text { de Maringá }\end{array}$ & Letras \\
\hline $\begin{array}{l}\text { 18. André } \\
\text { Aparecido Garcia }\end{array}$ & Dissertação & 2010 & Unicamp & Educação \\
\hline 19. Shirley da & Dissertação & 2011 & $\begin{array}{l}\text { Universidade Federal } \\
\text { do Rio de Janeiro }\end{array}$ & $\begin{array}{l}\text { Linguística } \\
\text { Aplicada } \\
\end{array}$ \\
\hline $\begin{array}{l}\text { 20. Vera Lucia } \\
\text { White }\end{array}$ & Dissertação & 2011 & $\begin{array}{l}\text { Universidade de São } \\
\text { Paulo }\end{array}$ & $\begin{array}{l}\text { Estudos } \\
\text { Linguísticos e } \\
\text { Literários em } \\
\text { Inglês }\end{array}$ \\
\hline
\end{tabular}



INTERFACE ESTUDOS DA TRADUÇÃO E LITERATURA INFANTOJUVENIL

\begin{tabular}{|c|c|c|c|c|}
\hline Autor & $\begin{array}{c}\text { Natureza } \\
\text { do trabalho }\end{array}$ & $\begin{array}{c}\text { Ano de } \\
\text { conclusão }\end{array}$ & Instituição & $\begin{array}{c}\text { Área do } \\
\text { conhecimento }\end{array}$ \\
\hline 21. Silvia Pozzati & Dissertação & 2014 & Universidade de São & $\begin{array}{c}\text { Língua, } \\
\text { Literatura e } \\
\text { Cultura } \\
\text { Italianas }\end{array}$ \\
\hline
\end{tabular}

\section{Natureza da Pesquisa}

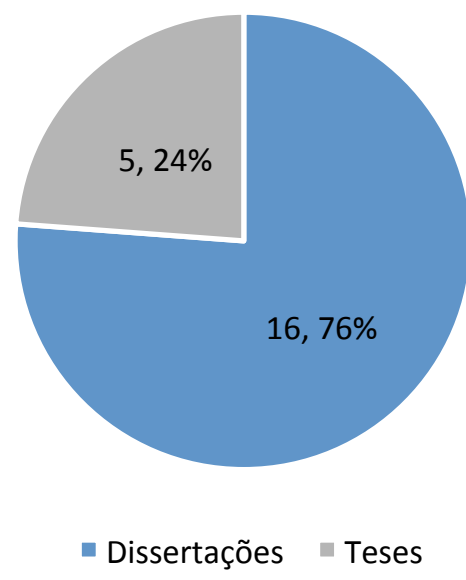

Gráfico 1 - Trabalhos separados por natureza: teses de doutorado e dissertações de mestrado.

Conforme demonstra o gráfico, a maioria dos trabalhos que investigam o papel de Lobato como tradutor de LIJ foram dissertações de mestrado. Isso indica que ainda são necessárias pesquisas que analisem de forma mais minuciosa esse fenômeno, já que, de acordo com Gile (2000) e reforçado por Grbic (2007), teses apresentam um maior aprofundamento do tema de pesquisa proposto.

\section{Ano de Defesa}

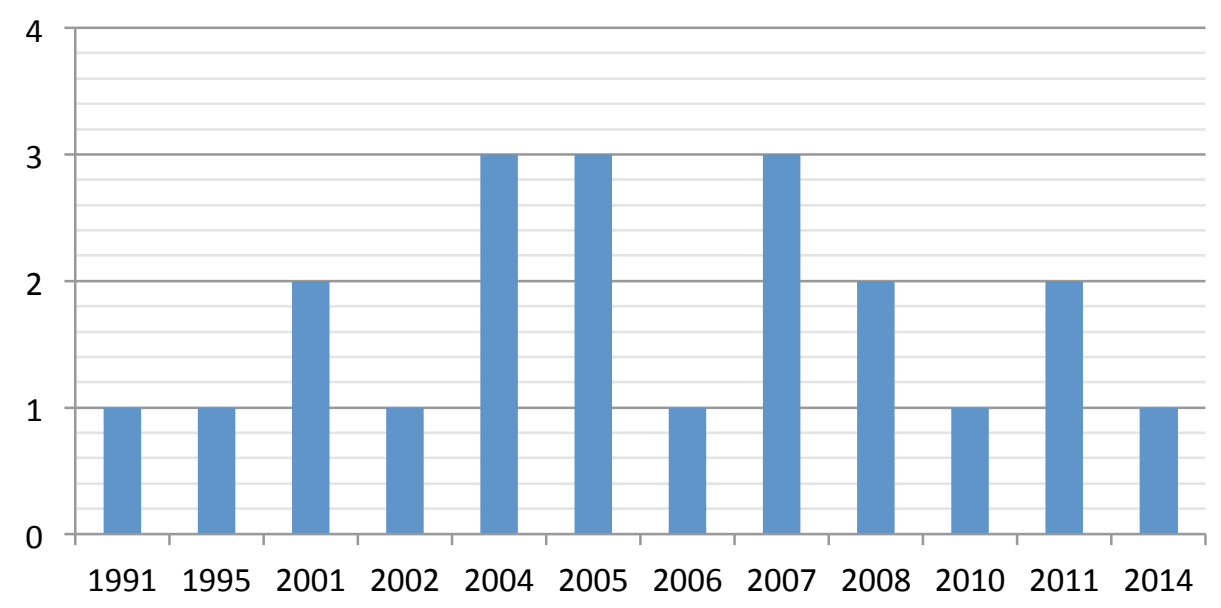

Gráfico 2 - Distribuição dos trabalhos por ano. 
Percebe-se que os trabalhos encontrados se concentraram a partir do ano de 2001 e que o número de trabalhos se distribuiu de maneira relativamente uniforme, não havendo grande concentração de trabalhos em um ano específico: o número máximo de trabalhos desenvolvidos dentro de um mesmo ano foi três. Não foi identificado um possível motivo para a maior parte dos trabalhos ter sido desenvolvida após os anos 2000, além do fato de ter havido crescente expansão da pós-graduação no território nacional (NETO; DUARTE ARAÚJO CASTRO, 2013).

Vale salientar que trabalhos anteriores à década de 1990 podem ter sido deixados de fora deste levantamento visto que, por ainda serem, em sua maioria, datilografados, poucos deles se encontram cadastrados no portal de Teses e Dissertações da CAPES, ou no "Domínio Público", e até mesmo nas bibliotecas digitais das universidades onde foram feitas as buscas.

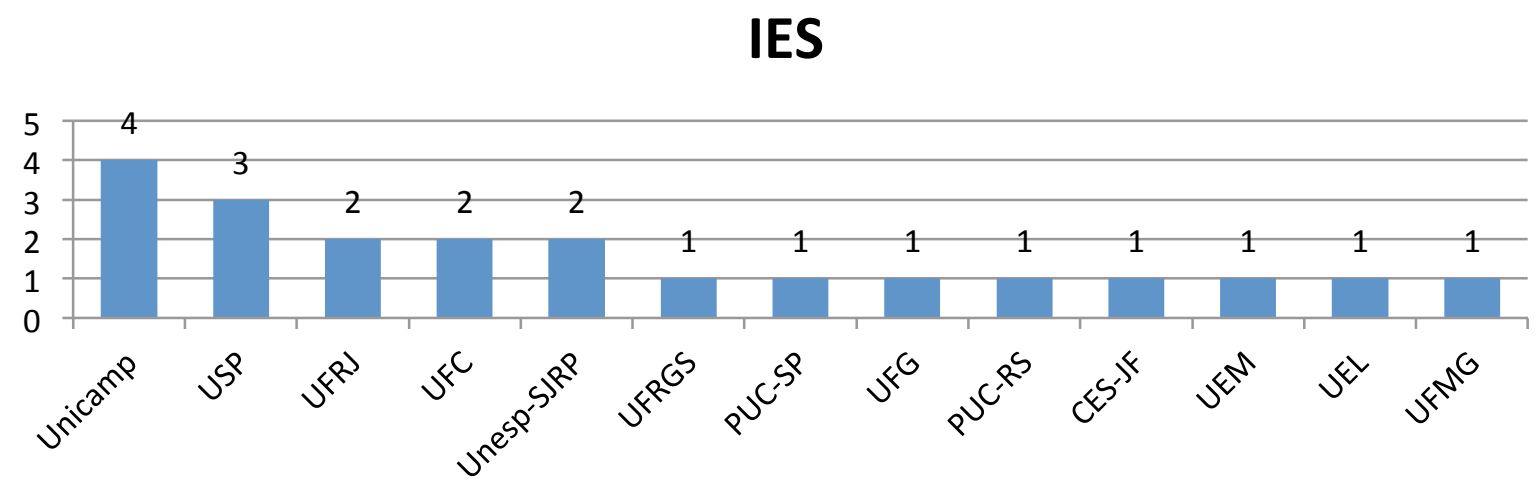

Gráfico 3 - Trabalhos defendidos em IES.

Como ilustra o Gráfico 3, a instituição com maior número de trabalhos defendidos é a Unicamp; entretanto, é curioso notar que essa é uma IES que não possui nem graduação nem pós-graduação específica na área de tradução. Os trabalhos defendidos junto à Unicamp se concentraram entre 2004 e 2010. Duas das pesquisas afiliaram-se ao nível de especialidade de Teoria e História Literária e as outras duas se afiliaram às áreas de Educação e à especialidade de Linguística Aplicada. É interessante observar que, apesar de a maior parte dos trabalhos terem se concentrado na subárea de Letras, a universidade com maior número de trabalhos defendidos não teve nenhuma de suas pesquisas filiadas a essa subárea. Um possível motivo para isso é o fato de a Unicamp apresentar programas de pósgraduação nas especialidades de Linguística Aplicada, Teoria e História Literária e na área de Educação.

A segunda instituição com maior número de trabalhos é a USP, que desde 2010 conta com pós-graduação strictu sensu em Tradução. Além disso, a USP teve, entre 1978 e 1981, um curso de graduação em tradução, que se transformou em 1982 em curso extracurricular e em 1991 em pós-graduação latu sensu, tendo sua última turma formada em 2006, quando o programa foi extinto (DEPARTAMENTO DE LETRAS MODERNAS, 2013).

Foi junto à USP que o primeiro trabalho encontrado na interface Lobato, Tradução e LIJ foi defendido, em 1991. Os outros dois trabalhos foram defendidos após um longo período de tempo, duas décadas depois, em 2011 e 2014. Assim como ocorreu no caso da Unicamp, a USP também não teve nenhum de seus trabalhos afiliados à área de Letras: o primeiro deles se afiliou à subárea de Linguística, o segundo à especialidade de Estudos 
Linguísticos e Literários em Inglês e o terceiro afiliou-se à especialidade de Língua, Literatura e Cultura Italianas - não cadastrado na tabela de áreas do conhecimento da CAPES (COMISSÃO DE APERFEIÇOAMENTO DE PESSOAL DE NÍVEL SUPERIOR, 2009).

Das instituições com dois trabalhos defendidos, a UFR e a UFC não têm nem curso de graduação nem pós-graduação strictu sensu em tradução, de acordo com sua página institucional na internet (UNIVERSIDADE FEDERAL DO CEARÁ, 2015a, 2015b; UNIVERSIDADE FEDERAL DO RIO DE JANEIRO, 2015a, 2015b). Já a Unesp de São José do Rio Preto não tem curso de pós-graduação em tradução (UNIVERSIDADE ESTADUAL PAULISTA JÚLIO DE MESQUITA FILHO, 2014), porém desde 1978 oferece curso de graduação de Bacharelado em Letras com Habilitação de Tradutor (UNIVERSIDADE ESTADUAL PAULISTA JÚLIO DE MESQUITA FILHO CAMPUS SÃO JOSÉ DO RIO PRETO, 2015).

Os trabalhos restantes foram desenvolvidos junto a oito universidades distintas que também não apresentam cursos nem de graduação nem de pós-graduação na área. Essa ampla distribuição pode se dar devido a motivos diversos, como os interesses de pesquisa dos professores orientadores.

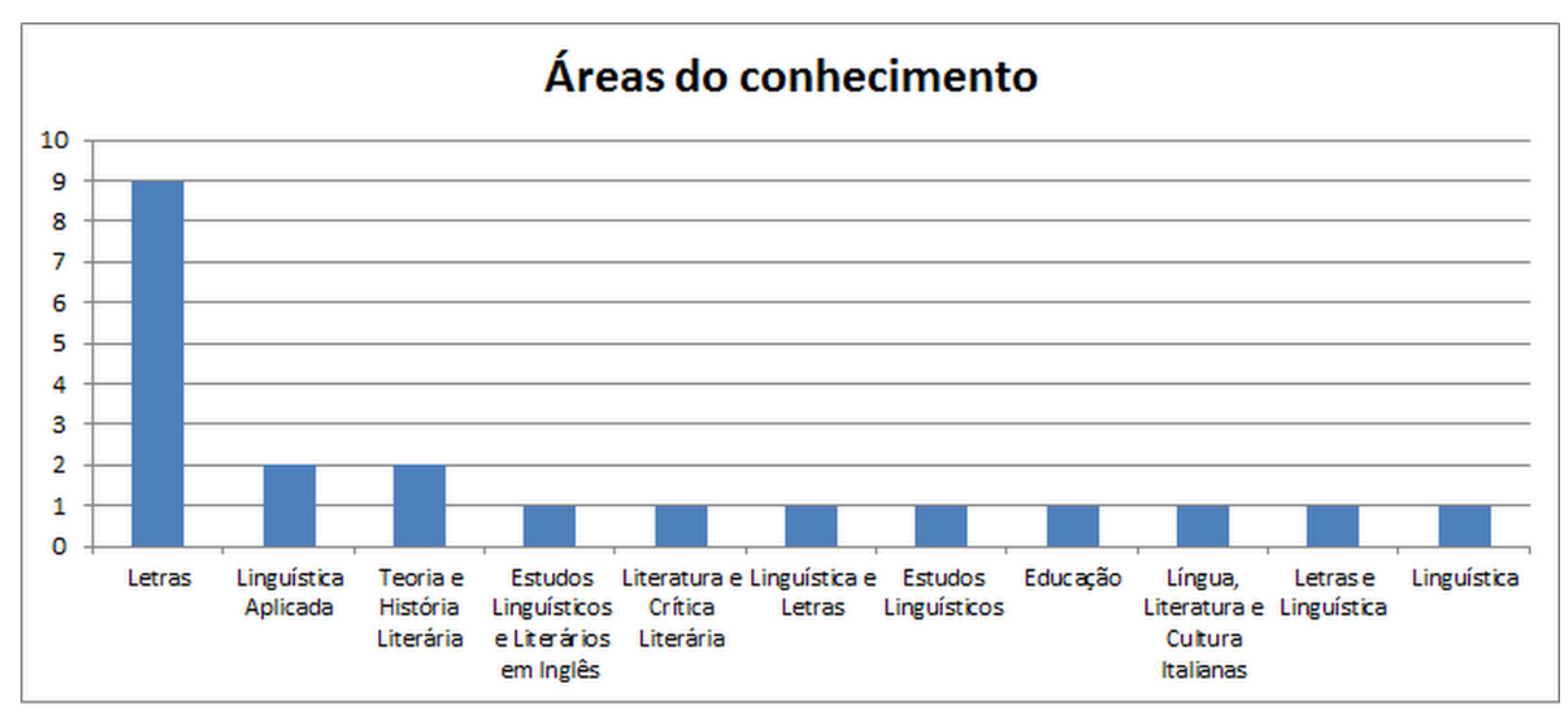

Gráfico 4 - Trabalhos separados por áreas do conhecimento.

No campo "áreas fins” do portal da Capes, com exceção de apenas um trabalho que se filiou à grande área da Educação, todos os demais se afiliaram à grande área de Linguística, Letras e Artes, o que já era esperado, já que investigam escritos literários. Conforme mencionado anteriormente, a maior parte dos trabalhos - 42,85\% - se filiou apenas à subárea de Letras (sem indicar a especialidade) e apenas um trabalho se filiou à subárea de Linguística. Já os demais trabalhos indicaram mais especificamente a especialidade - Linguística Aplicada e Teoria (e História) Literária - e outros registraram o nome do programa de pós-graduação no campo “áreas afins”. Essa falta de sistematização de registro do nível em grande área, área, subárea, especialidade e até mesmo o uso do nome do programa de pós-graduação no campo de “áreas afins” pode sinalizar a necessidade da maior diversificação da tabela da área de conhecimento da Capes, já que, 
por exemplo, a especialidade “Estudos da Tradução” não está contemplada, assim como outras especialidades.

\section{Considerações Finais}

O principal objetivo deste artigo foi demonstrar o papel dos estudos sobre Monteiro Lobato na consolidação da interface LIJ - ET. A pesquisa teve como objetivo oferecer um mapeamento da intersecção Monteiro Lobato, LIJ e ET, a partir de buscas feitas no portal de teses e dissertações da CAPES e das bibliotecas digitais das universidades brasileiras que oferecem graduação e pós-graduação stricto sensu em tradução.

Foram encontrados no total 21 trabalhos: 5 teses e 16 dissertações. Se levarmos em conta outro levantamento feito nos últimos dois anos (QUEIROGA, 2014), há 30 dissertações de mestrado e 6 teses de doutorado na interface LIJ-ET de forma geral. Assim, os estudos sobre as traduções de Lobato representariam cerca de $58 \%$ dos estudos na interface LIJ-ET, considerando-se que os termos de busca utilizados foram muito semelhantes nas metodologias deste e daquele estudo. Isso pode dar uma visão inicial de como as traduções feitas por Lobato e as obras traduzidas do autor geraram um grande interesse de pesquisa. Ademais, indicam a importância de sua produção como tradutor e como autor para a literatura nacional não adulta (e essas duas funções se entrelaçam constantemente, principalmente quando Lobato faz adaptações ou se apropria de personagens estrangeiros para criar sua própria ficção).

Os trabalhos encontrados por meio desta pesquisa revelam que a obra de Lobato pode ser analisada a partir de uma perspectiva multidisciplinar, uma vez que as teses e dissertações examinadas foram desenvolvidas em programas de Pós-Graduação de diversas áreas do conhecimento, como Letras, Linguística, Literatura e Educação, e que, ainda que por informações incompletas, pode-se perceber uma variedade de abordagens e metodologias empregadas. O caráter difuso apontado por Pagano e Vasconcellos (2003), portanto, ainda é característica dos Estudos da Tradução, e provavelmente "motiva a diversidade na afiliação de trabalhos acadêmicos sobre tradução a diferentes áreas e subáreas do conhecimento" (PAGANO; VASCONCELLOS, 2003, p.7).

Por fim, fica evidente a necessidade de realização de um mapeamento mais abrangente que investigue mais detalhes e outros tipos de produção acadêmica, como artigos de periódicos, monografias e trabalhos de conclusão de curso.

Caroline Reis Vieira Santos Rauta caroline.reis@ifsc.edu.br Profa. Dra., Instituto Federal de Santa Catarina

Elisângela Liberatti elisliberatti@hotmail.com Doutoranda em Estudos da Tradução, Universidade Federal de Santa Catarina 


\section{Referências bibliográficas}

Alencar, S. E. O. A. de. De Emília a Dona Quixotinha, uma aula de leitura com Monteiro Lobato. 282 p. Tese (doutorado) - Universidade Federal do Ceará, Programa de Pós-Graduação em Letras, Fortaleza, 2005.

Amorim, G. Dilma exalta papel das mulheres, que dirigem 85\% das escolas públicas. Rede Brasil Atual, 21 mar 2011.

Azevedo, C. L. de; Camargos, M.; Saccheta, V. Monteiro Lobato: furacão na Botocúndia. São Paulo: Senac, 1997.

BöHN, G. C. H. Peter Pan para crianças brasileiras: a adaptação de Monteiro Lobato para a obra de James Joice. 150p. Dissertação (mestrado) - Pontifícia Universidade Católica do Rio Grande do Sul, Programa de Pós-Graduação em Linguística e Letras, Porto Alegre, 2001.

CAvaleiro, E. Monteiro Lobato: vida e obra. São Paulo: Cia Editora Nacional, 1955. V. 2.

Cordeiro, M. S. Mark Twain na vitrine de Lobato. 148p. Dissertação (mestrado) Universidade Estadual de Londrina, Programa de Pós-Graduação em Letras, Londrina, 2005.

Cruz, S. da. Um passeio pelas diversas traduções de Alice no País das Maravilhas de Lewis Carroll no português do Brasil. 186 p. Dissertação (mestrado) - Universidade Federal do Rio de Janeiro, Programa de Pós-Graduação Interdisciplinar Linguística Aplicada, Rio de Janeiro, 2011.

FrancA, V. G. A Literatura Infantil/Juvenil brasileira na França: où est Lobatô? 160 p. Dissertação (mestrado) - Universidade Federal de Goiás, Programa de PósGraduação em Letras e Linguística, Goiânia, 2007.

. Nosso Jeca e nossa Emília vão ao exterior: as traduções das obras de Monteiro Lobato. Miscelânia: Revista da Pós-Graduação em Letras, v. 6, p. 40-57, 2009.

Garcia, A. A. Orlando Furioso de Lobato: uma obra inconclusa. 130 p. Dissertação (mestrado) - Universidade Estadual de Campinas, Programa de Pós-Graduação em Educação, Campinas, 2010.

Grbic, N. Where do We Come From? What Are We? Where Are We Going? A Bibliometrical Analysis of Writing and Research on Sign Language Interpreting. The Sign Language Translator and Interpreter, v. 1, n. 1, 2007.

LAJOLO, M.; Zilberman, R. Literatura Infantil Brasileira. 6a. ed. São Paulo: Ática, 1999.

Maximo, G. Duas personagens em uma Emília nas traduções de Monteiro Lobato. 103 p. Dissertação (mestrado) - Universidade Estadual de Campinas, Programa de PósGraduação em Linguística Aplicada, Campinas, 2004.

Mendes, D. R. Monteiro Lobato, As múltiplas faces do idealista: editor, tradutor e autor de obras infanto-juvenis. 70 p. Dissertação (mestrado) - Centro De Ensino Superior de Juiz de Fora, Programa de Pós-Graduação em Letras, Juiz de Fora, 2005.

Milton, J. The Political Adaptations of Monteiro Lobato. Cadernos de Tradução, v. 1, n. 11, p. 211-216, 2003.

OliveirA, M. L. S. de. Nas dobras da memória: a linguagem dos clássicos e suas adaptações. 176 p. Tese (doutorado) - Universidade Federal do Rio de Janeiro, Programa de Pós-Graduação em Letras, Rio de Janeiro, 2007. 
Pagano, A.; Vasconcellos, M. L. B. Estudos da Tradução no Brasil: Reflexões sobre Teses e Dissertações Elaboradas por Pesquisadores Brasileiros nas Décadas de 1980 e 1990. In: D.E.L.T.A. São Paulo: PUC-SP, 2003, v.19 n. Especial, p.1-25.

Pallotta, M. G. P. Uma História Meio Ao Contrário: Um Estudo Sobre "História Do Mundo Para As Crianças” De Monteiro Lobato. 403 p. Tese (doutorado) Universidade Estadual Paulista Júlio de Mesquisa Filho, Programa de PósGraduação em Letras, São José do Rio Preto, 2001.

Pozzati, S. A chave do tamanho: proposta de edição da obra de Monteiro Lobato na Itália. 107. Dissertação (mestrado) - Universidade de São Paulo, Programa de PósGraduação em Língua, Literatura e Cultura Italianas, São Paulo, 2014.

QueirogA, M. G. de. A voz da tradutora Clarice Lispector em livros infantojuvenis do gênero aventura. 224 p. Tese (doutorado) - Universidade Federal de Santa Catarina, Programa de Pós-Graduação em Estudos da Tradução, Florianópolis, 2014.

RodRIGUES, E. M. Forças motrizes de uma contística pré-modernista: o papel da tradução na obra ficcional de Monteiro Lobato. 183 p. Tese (doutorado) - Universidade Federal do Rio Grande do Sul, Programa de Pós-Graduação em Letras Porto Alegre, 2006.

Rocha, Pedro Albeirice da. Monteiro Lobato reescritor de Kipling. Tese de Doutorado (orientação Gentil Luiz de Faria). São José do Rio Preto, SP: Universidade Estadual Paulista, 2002.

SHAvit, Z. "Cheshire Puss,... Would you tell me, please, which way I ought to go from here?” Research of Children's Literature - The State of the art. How did we get there - how should we proceed. In: Cenitagoya, A. I. L.; León, E. L. Y; VÁzQUEZ, J. S. F. (Eds.). Realismo Social y Mundos Imaginarios: Una Convivencia para el Siglo XXI. Madrid: Universidad de Alcalá, 2003.

Silva, A. P. DOS S. Amoras Sem Espinhos: A Recepção De Fábulas (1922), De Monteiro Lobato, Por Crianças Do Ensino Fundamental. 272 p. Dissertação (mestrado) Universidade Estadual de Maringá, Programa de Pós-Graduação em Letras, Maringá 2008.

Trusen, S. M. Os Grimm no Sítio Do Picapau Amarelo: Tradução e Recepção dos Contos de Grimm em Monteiro Lobato. 144 p. Dissertação (mestrado) - Universidade Federal do Ceará, Programa de Pós-Graduação em Letras, Fortaleza, 1995.

VArgas, M. V. A. M. Do Pancatantra A La Fontaine: Tradução E Permanência da Fábula. 252 p. Tese (doutorado) - Universidade de São Paulo, Programa de Pós-Graduação em Linguística, São Paulo, 1991.

VIEIRA, A. S. Monteiro Lobato Translator. Crop, v. 1, n. 6, p. 143-169, 2001. . Viagens de Gulliver ao Brasil (Estudo das Adaptações de Gulliver's Travels por Carlos Jansen e por Monteiro Lobato). 216 p. Tese (doutorado) - Universidade Estadual de Campinas, Programa de Pós-Graduação em Teoria e História Literária, Campinas, 2004.

Volker, T. B. A Tradução das expressões idiomáticas por Monteiro Lobato em "The Adventures of Huckleberry Finn”: uma análise à luz da teoria da relevância. 15o p. Dissertação (mestrado) - Universidade Federal de Minas Gerais, Programa de PósGraduação em Estudos Linguísticos, Belo Horizonte, 2005. 

INTERFACE ESTUDOS DA TRADUÇÃO E LITERATURA INFANTOJUVENIL

White, V. L. A influência do filme de Walt Disney nas traduções e adaptações brasileiras de Peter Pan entre 1953 e 2011. 125 p. Dissertação (mestrado) - Universidade de São Paulo, Programa de Pós-Graduação em Estudos Linguísticos e Literários em Inglês, São Paulo, 2011.

ZorZato, L. B. A Cultura Alemã na Obra Infantil Aventuras de Hans Staden, de Monteiro Lobato. 182 p. Dissertação (mestrado) - Universidade Estadual de Campinas, Programa de Pós-Graduação em Teoria e História Literária, Campinas, 2007. 